to the tissues one of the gravest consequences of the anæmia has been, with some reason, associated - the granular degeneration of protoplasm, seen conspicuously in the muscular fibres of the heart, but affecting also all the protoplasm of the body. If this degeneration, as commonly believed, depends on the imperfect supply of oxygen to the tissues consequent on the deficiency in the number of the oxygen-carrying corpuscles, muscular exertion, by increasing the consumption of oxygen, must increase the tissue-deficiency. Absolute rest increases, therefore, the tissue-supply, and where the diminution of the corpuscles is so great as in this case, the increase in the tissue-supply of oxygen thas afforded is of the highest moment. The corpuscles were not far from the lowest point at which the processes of the body can go on. A reduction of another 10 per cent. would probably have placed the patient in immediate danger, from the effects of the tissue-deficiency of oxygen. ${ }^{3}$ It is to be remembered also that whatever be the origin of the red corpuscles, they must arise from and in active protoplasm, which will share the degenerative effect of the deficient supply of oxygen, and so, by increasing the relative tissue-supply, the development of the corpuscles in number and degree will be assisted. It was probably in part the effect of the anoxæmia on the developing protoplasm, which was shown by the altered form and granular appearence of the corpuscles of the blood immediately after admission.

(b) Nitrogenous food. Whatever be the nature of the tissue-degeneration anæmia causes, it is clearly due to defective nutrition of the protein tissues of the body, and by an abundant supply of protein material one essential element for the nutrition of those tissues may be secured. Such food was given as would tax as little as possible the digestive powers, since it must be remembered that the cells and fibres of the gastro-intestinal tract, on the function of which digestion so largely depends, will suffer the same degeneration, and be inadequate for heavy duty.

(c) Iron. It is intelligible that iron should increase the colour of red corpuscles; it is less easy to understand how it increases their number, although this is one of its best-established effects, of which the above case is a striking illustration. Iron must act as a direct stimulant to the process by which the red corpuscles are produced. According to the view almost universally received, the red corpuscles are produced by the transformation of leucocytes; the iron must act by increasing the formation of those cells, perhaps also by farouring their transformation. In this patient the white corpuscles, although at first in a slight relative excess, were really in an absolute deficiency. The preparation of iron used was the chloroxide, a nearly neutral form, selected on account of the eridence of gastric irritability. It consists of a solution of oxide of iron (obtained by precipitate from the perchloride) in the ordinary solution of perchloride of iron.

3. On each occasion menstruation was attended by a considerable diminution in the number of red corpuscles. It marked chiefly the first few days of the menstrual period, a rise occurring during the latter part. In one instance at least the fall in the corpuscles distinctly preceded the establishment of the menstrual flow-a fact which is in harmony with the pale appearance sometimes observable before menstruation actually begins. This would suggest that the diminution in the number of the corpuscles is not due merely to their loss in the flow, but rather to an associated interference with the process of blood-formation,

4. The cardiac condition in this case is of great interest, and was the subject of a number of very careful observations, but to describe these at length would be foreign to the immediate purpose for which the case is now narrated. The most conspicuous disturbance was the over-action of the heart in frequency as well as in force. The pulse was incompressible, partly perhaps from the frequency of the heart's action. The rate was uniformly 108 per minute (without ferer, excitement, alcohol, or anything to cause it) as long as the corpuseles were below 40 per cent. of the normal, and the attainment of this percentage was accompanied by a sudden fall of 20 beats. The lower rate was maintained for sereral weeks. No cardiac sedative was administered.

Queen Anne-street, $\mathrm{W}$.

${ }^{3}$ In a case of death from hæmorrbage $I$ found that just before death the corpuscles had fallen to 9 per cent. Death occurred rapidly. It is doubtful whether life can be carried on for long with less than 15 per cent.

\title{
THE INFECTIOUS NATURE OF YELLOW FEVER.
}

BY JAMES J. L. DONNET, M.D.,

INSPECTOR-GENERAL OF HOSPITALS AND FLEETS; HONORARY SURGEON TO THE QUEEN.

IN the article, "Is Yellow Fever Infectious?" which appeared in The LANCET of the 27th October last, Dr. Cargill, of Jamaica, has opened a subject of much interest to the medical world at large, and one of vital moment to the inhabitants of the West Indies.

Since the discovery of America by Columbus, the question of the infectious nature of yellow fever has agitated the medical mind, and much diversity of opinion has obtained regarding it, many names of authority being ranged on the side of infection, whilst as many and as authoritative are found on that of its non-infectious nature. The experience which I have had respecting the various forms of fevers observed in tropical and warm climates (an experience based upon the many instances of these fevers which have fallen under my observation) has forced me to the conclusion that yellow fever proper is a fever of a highly infectious nature, varying in intensity with the degree of virulence which accompanies it, and with the cosmic and atmospheric influences reigning at the time; and I cannot consider the want of unity of opinion which obtains regarding its infectious properties, otherwise than as a misconception. arising from the seeming analogy which links one form of fever with the other, and which, as a blinding cloud, has shrouded the true nature of the disease and has forced the observers into inferences drawn from erroneous premises.

The shades which separate the symptoms of one fever from those of another, in warm climates, are sometimes of such gentle gradation that prim $\hat{x}$ facie they seem to belong to one and the same disease, and this more especially refers to the yellow and remittent class of fevers, between which so slight is sometimes the distinction, that remittent has frequently been considered and classified as true yellow fever; for in the prominent symptoms which present in both yellow and remittent fever a great similarity obtains : both take their origin in paludal soils, both in their course offer symptoms of so seemingly similar a nature, that the shades which differentiate them are so slight as to frequently escape the conscientious observer and cause him to fall into indefensible interpretations. But this apparent similarity vanishes on close and continuous inspection, for then essential and distinctive marks are observed, which stamp each with an individuality, and which characterise each as a separate disease, distinct in its essence and differing significantly one from the other. These differences may be summarised as follows :-

\section{Yellow Fever.}

Is essentially of an infectious nature.

Only vigorous and young constitutions fall victims to it. Coloured population less liable than white.

Restricted to the yellow fever zone-namely, the delta of the Mississippi, and the adjoining coasts and islands.

Is of a continued type; no remissions.

Rachialgia more pronounced in this fever than in any other, except small-pox.

Abstraction of blood not tolerated.

Albuminous urine the rule.

Liver affected.

Spleen not affected.

Partial or total suppression of urine the rule.

Hamorrhages from stomach in bad cases the rule.
Remittent Fcver.

Is not of an infectious nature.

All ages and constitutions are liable, and the weakest most so. Coloured population as liable as white.

Is to be found in all parts of the world where marshy soils prevail.

Remissions observed in the morning.

Rachialgia slight.

Abstraction of blood tolerated.

Albuminous urine the exception.

Liver not affected.

Spleen invariably affected.

Suppression of urine the exception.

Hremorrhages from the stomach in bad cases the exception. 
Quinine useless as a thera- Antagonisticpower of quinine peutic agent.

Death occurs on the fifth day. beyon.

Yellow fever never merges into intermittent.

One attack affords an immunity from future ones.

Immunity almost perfect after a three years' residence in the lowlands.

Convalescence less protracted than in remittent fever.

Peculiar smell in yellow fever Not observable in remittent cases. fever.

These distinctions are striking; yet there are many who hesitate in determining what the points of contact and divergence are which connect and separate the various forms of malarious disorders. From their having observed yellow fever to coexist with remittent, they believe that both remittent and yellow fever are due to one and the same cause that upon a reciprocal action of various concurrent agents, and a varied mode of operation of the cause, depend the varied conditions which are observed; and they ask why should not the relation between the two conditions be one of direct causation? These inferences, however, are drawn from observations limited to the habitat of yellow fever, and consequently are not sufficiently cumulative to warrant their acceptance. For if yellow fever and remittent be the offspring of one and the same germ, then yellow fever should be found wheresoever remittent fever has existence; but yellow fever is unknown in the vast marshes at the deltas of the large rivers of the Old World, and in the many localities in which remittent fever luxuriates. This coincidence of the appearance of two disorders in one locality has likewise been noted by others. Sir James M'Grigor observed during the Peninsular war that when men were encamped by the side of some rivers, a part would fall subject to dysentery, whilst another would be attacked by ague.

Whilst doing duty as medical officer with the men of the Royal Marine Battalion, quartered at St. Jean d'Acre after the fall of that fortress, I observed that whilst a portion of them fell ill of dysentery, another succumbed to remittent fever. The same thing occurred to the men exposed to the baneful influences of the Gold Coast during the Ashantee campaign, for whilst some had fever of a remittent type, others suffered from malarious dysentery.

The advocates of the exclusive existence of one germ for the manifestation of two different diseases in one locality, allege such examples as the above in support of their theory; the poison, they say, acts variously according to the constitution and the influences reigning at the time. If we admit the theory that one cause alone is sufficient to produce different diseases as distinct in themselves as are yellow and remittent fever, we should then find ourselves in the position of being obliged to break down the barriers which now are generally admitted to divide scarlet fever from measles, yellow fever from plague, typhus fever from typhoid, rabies from hydrophobia, and to accept theories which are diametrically opposed to received opinions, and directly at issue with the facts and evidence which have been solved by accurate research and clinical observation. In the West Indies, simple continued fever and remittent fever may be found coexisting, whilst yellow fever is prevailing and doing its worst; but it does not follow, because different types of fever appear during the prevalence of a more severe one, such as yellow fever is, that any necessary causative connexion exists between them.

Whatsoever be the cause or whatsoever the germ which originates yellow fever, there is every reason to believe that it is essentially the cause or specific germ of yellow fever, differing toto celo from that which produces remittent fever or dysentery; and in the histories of the various epidemies of yellow fever which have occurred since the seventeenth century, whether deseribed by a Ferreira da Rosa, a Simaõ da Cunha, a Chisholm, a Rush, a Blair, or a Louis, this fever is stamped with an individuality which prevents it from being mistaken for plague or remittent or other fever.

Wheresoever malarious diseases have appeared they have been characterised similarly, and although some shades of difference do obtain, as in all types of fever, these diseases have always been identical, in their essential symptoms, with those from whence they have sprung, and have pre. served their individuality from ages most remote. The plague which is cradled in the delta of the Nile has always produced the symptoms of plague. Cholera, which is the child of the Sonderbunds of the Ganges, has always produced cholera. Yellow fever, which finds its birth in the delta of the Mississippi, invariably engenders yellow fever. Each has produced nothing more nor less than itself but in degree ; and as Professor Tyndall, in his lectures at the Royal Institution, has said :- "As surely as a thistle was from a thistle seed, as surely as a fig comes from the fig, the grape from the grape, the thorn from the thorn, so surely does the typhoid fever virus increase and multiply into typhoid fever, the scarlatina virus into scarlet fever, the small-pox virus into small-pox." And so with yellow and remittent fever, each distinct in itself, each having a germ sui generis, a germ endowed with like and constant properties, indicated in its effects by special symptoms during life, and specific pathological lesions revealed by examination after death. Remittent fever clothed in similar symptoms reveals itself as remittent and never as yellow fever, whilst yellow fever assumes an individuality which stamps it as a specific disease, essentially infectious in its nature, distinct and separate from remittent.

Cheltenhana.

\section{A CASE OF FREQUENT REMARKABLY HIGH TEMPERATURES DURING AND AFTER CONVALESCENCE FROM ENTERIC FEVER.}

BY HORATIO DONKIN, M.B. OxoN., SENIOR ASSISTANT-PHYSICIAN TO WESTMINGTER HOSPITAL; PHYSICIAN TO THE EAST LONDON HOSPITAL FOR CHILDREN.

THE subject of these remarks is a nurse at the East London Hospital for Children, aged nineteen, who came under my notice early in January of this year, suffering from enteric fever. She first took to her bed on Jan. 13th, having, however, had considerable diarrhœa for a week previously, and confessing to having felt very unwell since the beginning of the month. The diarrhoea continuing and a few rose spots still making their appearance, the temperature steadily rose from the morning of the 14th, till, on the 17 th, there was a morning temperature of $105^{\circ}$ and an even. ing one of $105.5^{\circ}$. On the 18 th the morning registration showed $105 \% 2^{\circ}$, while in the evening of that day a tempera. ture of only $98.5^{\circ}$ was noted in the axilla, a thermometer in the mouth shortly afterwards showing $100^{\circ}$. There was no obvious change in other symptoms with this fall, nor was there at any time evidence of danger independently of the height of the temperature. From the 19th to the 2Ist inclusive no lower temperature was remarked than $104^{\circ}$, the observations being made thrice daily; and on the evening of the 21 st the temperature rose from $105^{\circ}$ at 6 P.M. (about which point the maximum had previously been) to $109^{\circ} 4^{\circ}$ at 8.30 P.M. (On the afternoon of this day, when I saw her between 4 and 5 o'clock, the patient appeared about at her worst, being somewhat prostrate and lying low down in the bed.) According to my instructions, should the temperature rise above $105^{\circ}$, she was put into a bath at $90^{\circ}$, to be gradually cooled to $60^{\circ}$. After ten minutes of the bath a ther. mometer in the mouth showed $97 \cdot 6^{\circ}$, and the patient shivered. She was, however, kept in the bath for twenty-five minutes. After some violent shivering for about an hour, the temperature, which had been $96^{\circ} 8^{\circ}$, rose to $98.6^{\circ}$, and fluctuated through the night between $97.8^{\circ}$ and $98^{\circ} 6^{\circ}$. The next morm. ing the patient seemed in every respect better than on the previous afternoon. No diarrhœea occurred after this date, nor was any complaint made beyond that of more or less abdominal pain, which has occurred at intervals up to the present time. At the time of the high temperature no extra heat of skin was noticed, and the pulse-beats were only SS.

The records of temperature from this date till the 25th show variations between $96.4^{\circ} \mathrm{F}$, and $99.6^{\circ}$. On the 25 th the temperature gradually rose through the day from $97^{\circ}$ to $104 \cdot 8^{3}$ at 11 P.M., reaching at midnight $110^{\circ}$. This temperature was registered a second time by the same thermometer immediately afterwards. After a short interval $109^{\circ}$ was registered by another thermometer. Upon this the resident 